\title{
Factors affecting executive functions in obstructive sleep apnea syndrome and volumetric changes in the prefrontal cortex
}

\author{
Zahide Yılmaz ${ }^{*}$, Nuray Voyvoda ${ }^{2}$, Eda İnan ${ }^{3}$, Pınar Bekdik Şirinocak ${ }^{1}$ and Rabia Terzi ${ }^{4}$
}

\author{
*Correspondence: \\ yilmazzahide@hotmail.com \\ ${ }^{1}$ Clinic of Neurology, \\ Kocaeli Derince Education \\ and Research Hospital, \\ Kocaeli, Turkey \\ Full list of author information \\ is available at the end of the \\ article
}

\begin{abstract}
Purpose: Obstructive sleep apnea syndrome (OSAS) is associated with cognitive changes and executive functions are among the cognitive domains most affected. However, it is not completely understood which of the factor(s) among hypoxemia, repeated arousal, and sleepiness affect the executive functions. This study aims to evaluate the possible relationship between the executive functions and nocturnal parameters, Epworth Sleepiness Scale (ESS) scores, and prefrontal cortex (PFC) volumes.

Patients and methods: A total of 28 patients aged between 18 and 60 years who were newly diagnosed with OSAS were included in this study. The Wisconsin Card Sorting Test (WCST) and Stroop test which were used in the evaluation of executive functions were applied to all patients. Cranial magnetic resonance imaging (MRI) and volumetric measurements of the PFC were performed. Polysomnography (PSG), WCST, Stroop test, and cranial MRI were also applied to the control group which consisted of age- and education status-matched 15 healthy subjects. The correlation of WCST and Stroop tests and PFC volume, PSG parameters, and ESS scale was examined.

Results: The WCST- 6 test scores were statistically significantly higher in the patient group ( $p=0.022 ; p<0.05)$. Additionally, the Stroop test $5(p=0.043)$ and Stroop test-5 correction $(p=0.005)$ measurements were statistically significantly higher in the patient group $(p<0.05)$. A negative and statistically significant correlation was found between the WCST-4 and WCST-10 and ESS measurements in the patient group ( $r$ $-0.452 ; p 0.016 ; p<0.05 ; r-0.437 ; p 0.020 ; p<0.05)$. However, there was no correlation between the PSG parameters and WCST and Stroop test scores. No statistically significant differences in the MRI volumetric measurements of the PFC were found between the patient and control groups.

Conclusions: Impairment in the attentive and executive functions in OSAS is evident. The most influential factor is excessive daytime sleepiness, rather than hypoxemia and severity of the disease.
\end{abstract}

Keywords: Executive function, Prefrontal cortex, Obstructive sleep apnea, Excessive daytime sleepiness, Hypoxemia

\section{Background}

Obstructive sleep apnea syndrome (OSAS) is a common disorder of breathing during sleep characterized by repeated obstruction of the upper airway. The resolution of airway obstruction is accompanied by arousal from sleep (Borak et al. 1996).

(c) The Author(s) 2016. This article is distributed under the terms of the Creative Commons Attribution 4.0 International License (http://creativecommons.org/licenses/by/4.0/), which permits unrestricted use, distribution, and reproduction in any medium, provided you give appropriate credit to the original author(s) and the source, provide a link to the Creative Commons license, and indicate if changes were made. 
Obstructive sleep apnea syndrome is accompanied by cognitive disorders. Among the cognitive domains most affected is the executive function (Saunamaki and Jehkonen 2007). Currently, the most widely accepted view is that neurocognitive impairment in OSAS is due to adverse effects of sleep fragmentation or intermittent hypoxia (Bucks et al. 2013). However, it is still unclear whether neurocognitive impairment is associated with excessive daytime sleepiness caused by chronic sleep fragmentation or with repeated apnea episodes. Sleep fragmentation may also mediate the cognitive deficits in OSAS via dysfunction in neural networks, particularly in the frontal lobes. The basis of the hypothesis is that sleep disruption reduces the efficacy of restorative processes in the prefrontal cortex (Horne 1998; Maquet 1995).

Beebe and Gozal defined the executive functions in six different subgroups as follows: behavioral inhibition, set-shifting, self-regulation of affection and arousal, working memory, analysis/synthesis, and contextual memory (Beebe and Gozal 2002). The Wisconsin Card Sorting Test (WCST) is the main tool to measure the executive functions (Baddeley et al. 1986; Lezak 1995; Pennington and Ozonoff 1996). Another widely used test to measure the executive functions is the Stroop test (Spreen and Strauss 2007). The WCST and Stroop tasks have been shown by functional magnetic resonance imaging (MRI) in neuroradiology to be associated with different regions of the prefrontal area; findings obtained under the Stroop test have been localized, particularly in the left frontal lobe, while the WCST performance has been localized mainly in the right frontal lobe (Karakaş and Karakaş 2000; Yaouhı et al. 2009).

In this study, we aimed to evaluate the executive functions in mild to severe OSAS and control groups using the WCST and Stroop test. Volumetric measurements of the prefrontal cortex (PFC) were performed by cranial MRI in the same patient group and we also investigated possible correlations of the findings with polysomnography (PSG) parameters and the Epworth Sleepiness Scale (ESS).

\section{Patients and methods}

A written informed consent was obtained from each subject. The study protocol was approved by the local Ethics Committee. The study was conducted in accordance with the principles of the Declaration of Helsinki.

Patients who were newly diagnosed with OSAS at the Sleep and Sleep Disorders Laboratory of the Neurology Clinic at Kocaeli Derince Education and Research Hospital between 01.2012 and 12.2014 were included in the study. Patients aged between 18 and 60 years were evaluated. Patients with neurological diseases, mental disorders, severe psychiatric diseases, previous cancer, and other sleep disorders including central sleep apnea syndrome, periodic limb movement disorder, narcolepsy, and restless legs syndrome were excluded from the study. Patients were questioned for hypertension (HT), diabetes mellitus (DM), heart disease, and chronic obstructive pulmonary disease (COPD). The WCST and Stroop tests were performed in all patients by an experienced psychologist and cranial MRIs were obtained. A control group consisted of 15 age- and education status-matched healthy individuals.

The level of education of the patients were divided in three levels, as education duration of five years, between 8 and 12 years, and $\geq 13$ years, defined as low, intermediate, and high education status, respectively. 
The control group also received PSG, WCST, and Stroop tests, and cranial MRI were performed. Body mass index (BMI) was also calculated in all patients and controls. A full night PSG was performed in all patients and individuals of the control group at the sleep laboratory. The PSG included electroencephalography, electrooculography, chin and leg electromyography, electrocardiography, snoring, thermistor, nasal pressure transducer, finger pulse oximeter, thoracic and abdominal respiratory movements, and body position. Scoring was performed according to the 2010 American Academy of Sleep Medicine criteria. Patients with an Apnea/Hypopnea Index (AHI) of equal to or more than $5 / \mathrm{h}$ were accepted to have OSAS. An AHI value equal to or greater than $5 / \mathrm{h}$ and $<15 / \mathrm{h}$ was defined as mild; an AHI value equal to or greater than $15 / \mathrm{h}$ and less than $30 / \mathrm{h}$ was defined as moderate, and an AHI value more than $30 / \mathrm{h}$ was defined as severe OSAS.

\section{Magnetic resonance imaging}

Magnetic resonance imaging examinations of the patient and control groups were performed using the same MRI equipment (1,5 Tesla, Intera Master, Philips Medical Systems, USA) and a standard head spiral. In addition to the conventional MRI examination, A 2-mm section was obtained with inversion recovery (IR) placed at the coronal plane with the TSE method (TR/TE/TI: 2250/10/400 msn, NSA: 2, TSE factor 15). An IRTSE examination was used for volumetric measurements. All images were transferred to a $\mathrm{CD}$ and the measurements were performed on another computer by the same radiologist who was blind to the both patient and control groups.

The right and left sides were evaluated separately in the prefrontal cortex. Sections from the anterior frontal lobe to the anterior genu of the corpus callosum were evaluated. The gray matter area was calculated using mathematical subtraction following the measurement of the area of the total PFC (white matter and gray matter) and the area of white matter (Fig. 1). These areas were multiplied by the thickness of the cross section, and volumetric data (raw data) was, then, obtained (Rademacher et al. 1992).

Since the magnitude of the head is variable in each individual, corrected volumes of those structures were calculated according to the formula used in the study by Watson et al. (1997) and Insausti et al. (1998).

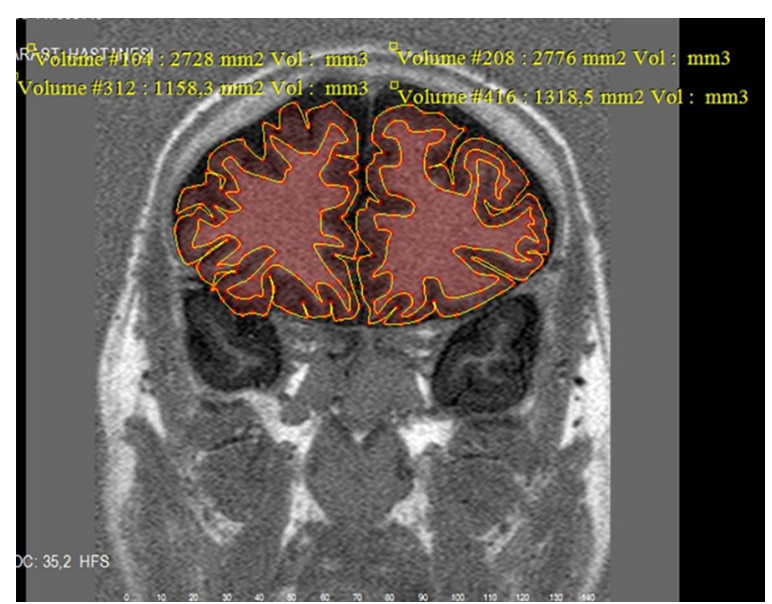

Fig. 1 Areas of total and white matter of right and left prefrontal cortex were calculated 
Corrected volume $=[($ Mean intracranial area of all cases/the intracranial area of the case $)$ $\times$ raw data volume of the case]

For normalization, the section in which anterior commissure was present at the coronal IR sequence in the MRI examination of the patient and control groups was defined and the intracranial area of this level was measured. Intracranial area of all cases was calculated and divided into the intracranial area of the case. The calculation of this value with the raw data volume which was measured manually yielded the calculation of separate corrected volume values in each patient (Fig. 1).

\section{Neuropsychological examination}

One of the main tests used in measuring the executive functions is the WCST (Karakaş and Karakaş 2000). Primarily, the perseveration and abstract scrutinizing; concept formation; defining property; attention; working memory; mental flexibility; problem solving; category creation; and changing categories are among the specifications which WCST is able to measure. The WCST, which is used as a frontal lobe test, is lateralized to the right hemisphere (Karakaş and Karakaş 2000) and has a distribution in the right frontal lobe including the dorsolateral PFC (Karakaş 2006). Normative data of the WCST were collected in the context of the Neuropsychological Test for Cognitive Potentials Battery. Two decks consisting of four stimulating cards and 64 test cards are included in the WCST test. The patient chooses a card from above the first deck and he/she should find the stimulating that card matches (matching is expected to be made according to the color, shape, or amount for two cycles) with the card he/she picks. While the instructions are given, no hints should be given to the patient about how and according to what the cards should be matched. Feedback should be given to the patient after each match on whether the matching is correct or not, and the patient should be expected to find the matching rule. The test is complete, when the patient completes six categories or when he/she uses all 128 cards. Scoring is performed according to a total of 13 categories, which are total number of answers, total number of erroneous answers, total number of correct answers, number of completed categories, perseverative responses, perseverative errors, non-perseverative errors, percentage of perseverative errors, number of trials used to find the first category, percentage of cognitive level response, points for failure to continue setup, point for learning how to learn, and points for failure to learn to learn (Karakaş 2006). In this study, the WCST-2 (total number of errors), WCST-4 (number of completed categories), WCST-6 (total number of perseverative errors), and WCST-10 (number of cognitive level responses) were included. When the patient insists on using previous principles and does not change the principle (perseveration), although the behavioral principle has been changed and he/she has received warning directions on this subject by the tester, it implies impairment in performance (Karakaş and Karakaş 2000).

In addition, we used the Stroop test, which is utilized to measure attention, in addition to executive functions. The Stroop test used in Turkey is prepared using the combination of original Stroop test and Victoria form of the Stroop test in the context of Neuropsychological Test for Cognitive Potentials Battery. Its reliability and validity tests were performed and normative data were collected. The form created as the Stroop test 
was called Basic Sciences Research Group (BSRG) Form (Karakaş 2006). The Stroop test measures the speed of data processing and attentive skills, mainly cognitive setup and responsive skills under destructive effects (Karakaş 2006).

There are four cards used in the Stroop test. In the first card, there are words of color names printed with black ink. The second card involves the same words of color names printed in different colors (e.g., the word 'red' printed with green ink), in the third card, there are colored circles and in the fourth card, there are neutral words (Turkish words; kadar, zayıf, ise, orta) printed in different colors.

During the test, the patient is asked to read the words of the color names printed in black in the first section (first card), to read the words of color names printed in different color, but not to tell the color of ink in the second section (second card), tell the names of the colors of colored circles in the third section (third card), tell the printed color of the word, but not to read the word (neutral Turkish words; kadar, zaylf, ise, orta) in the fourth section (fourth card). Finally, in the fifth section, the patient is asked to tell the printed the colors of the word, but not to read the word and tell red, but not green for the word 'green' printed in red-(second card again).

Impairment in performance is defined as lengthening of the duration of telling the colors with inability to resist the accustomed response (reading) or as telling the wrong color. Patients with a low resistance to interference and who are unable to cope with distractors read the article instead of telling the color. Spontaneous corrections and errors and time are recorded during scoring. Duration of reading the words printed in colored letters was subtracted from the duration of the section in which the patient told the colors, instead of reading the words. If this difference of duration is high and a high number of errors and spontaneous corrections is present, it indicates that the attention of the individual can be easily distracted and that the individual has difficulty in suppressing an inappropriate response tendency (Oktem 2006). The Stroop test performance is particularly associated with the left frontal lobe (Karakaş 2006). It is also quite sensitive to the frontal function disorders (Oktem 2006).

Furthermore, the patients were also evaluated using the ESS. It was used in the measurement of daily sleepiness condition of the patients (Karakoç et al. 2007; Izci et al. 2008). Patients with an ESS score $>10$ were considered to have excessive daytime sleepiness.

\section{Statistical analysis}

The NCSS (Number Cruncher Statistical System) 2007 (Kaysville, Utah, USA) software was used for statistical analysis. Descriptive data were expressed in mean, standard deviation, median, frequency, percentage, and minimum and maximum values. The Mann-Whitney U test was used to compare two groups without normal distribution, while the Kruskal-Wallis test was used to compare the quantitative variables of three groups. Qualitative variables were also compared using the Pearson's Chi square and Fisher's exact tests. The Spearman's correlation analysis was used to analyze correlations between the variables. $p$ values of $<0.01$ and $<0.05$ were considered statistically significant. 


\section{Results}

Of a total of 43 subjects, $26(60.5 \%)$ were males and 17 (39.5\%) were females with a mean age of $44.53 \pm 8.08$ (range 28-60) years (Table 1 ). There was no statistically significant difference in the mean age, sex distribution, and education status between the patient and control groups $(\mathrm{p}>0.05)$. The BMIs of the cases in the patient group were statistically significantly higher, compared to the controls $(\mathrm{p}=0.007 ; \mathrm{p}<0.01$ ). In addition, ESS scores were statistically significantly higher in the patient group, compared to the control group ( $\mathrm{p}<0.05$ ). The incidence of HT, cardiac disease, COPD, and DM was similar between the patient and control groups ( $\mathrm{p}>0.05$ ). The AHI and Time $\mathrm{SO}_{2}<90 \%$ measurements were also statistically significantly higher in the patient group, compared to the control group $(\mathrm{p}=0.001 ; \mathrm{p}<0.01)$. However, $\min \mathrm{SO}_{2} \%$ measurements were statistically significantly lower in the patient group, compared to the control group $(\mathrm{p}=0.001 ; \mathrm{p}<0.01)$. There was no statistically significant difference in the non-rapid eye movement (NREM)1\%, NREM2\%, NREM3\%, and rapid eye movement (REM) \% measurements between the groups ( $\mathrm{p}>0.05$ ) (Table 2). No statistically significant differences were found in the PFC right total, white matter, gray matter (subtraction) and PFC left total, and white matter and gray matter (subtraction) MRI volumetric measurements (p > 0.05) (Table 3).

The WCST-2 and WCST-10 test measurements were higher in the patient group; WCST-4 was lower in the patient group and $p$ values were close to statistical significance. However, no statistically significant difference was found between the two groups ( $\mathrm{p}>0.05)$. The WCST-6 test was statistically significantly higher in the patient group $(\mathrm{p}=0.022 ; \mathrm{p}<0.05)$. In the patient group, the Stroop test-5 $(\mathrm{p}=0.043)$ and Stroop test -5 correction $(\mathrm{p}=0.005)$ measurements were also statistically significantly higher,

Table 1 Demographic characteristics of patient and control groups

\begin{tabular}{|c|c|c|c|c|}
\hline & Total $(n=43)$ & Patient $(n=28)$ & Control $(n=15)$ & $\mathrm{p}$ \\
\hline \multicolumn{5}{|l|}{ Age (years) } \\
\hline Min-max (median) & $28-60(45)$ & $32-60(46)$ & $28-57(40)$ & $0.054^{a}$ \\
\hline \multicolumn{5}{|l|}{$\mathrm{BMI}\left(\mathrm{kg} / \mathrm{m}^{2}\right)$} \\
\hline Min-max (median) & $21.50-44.30(31.3)$ & $22.80-44.30(32.5)$ & $21.50-41.40(26)$ & $0.007^{a, * *}$ \\
\hline \multicolumn{5}{|l|}{ Sex } \\
\hline Male & $26(60.5)$ & 19 (67.9) & $7(46.7)$ & $0.176^{b}$ \\
\hline Female & $17(39.5)$ & $9(32.1)$ & $8(53.3)$ & \\
\hline \multicolumn{5}{|c|}{ Duration of education (years) } \\
\hline Min-max (median) & $1-15(7)$ & $1-12(6)$ & $5-15(8)$ & 0.178 \\
\hline \multicolumn{5}{|l|}{ Education status } \\
\hline Low education & $22(51.2)$ & $16(57.1)$ & $6(40.0)$ & \\
\hline Intermediate education & $17(39.5)$ & $12(42.9)$ & $5(33.3)$ & \\
\hline High education & $4(9.3)$ & 0 & $4(26.7)$ & \\
\hline \multicolumn{5}{|l|}{ ESS } \\
\hline Min-max (median) & $0-19(10)$ & $1-19(11.5)$ & $0-14(6)$ & $0.036^{*}$ \\
\hline \multicolumn{5}{|l|}{$B M I$ body mass index } \\
\hline \multicolumn{5}{|l|}{${ }^{*} \mathrm{p} p<0.01 ; * \mathrm{p}<0.05$} \\
\hline \multicolumn{5}{|l|}{ a Mann-Whitney U-test } \\
\hline \multicolumn{5}{|l|}{ b Pearson's Chi square test } \\
\hline c Fisher's exact test & & & & \\
\hline
\end{tabular}


compared to the control group ( $\mathrm{p}<0.05)$. No statistically significant differences were found in the Stroop test- 5 error measurements ( $>0.05$ ) (Table 4).

Furthermore, no statistically significant difference was found in the MRI volumetric measurements of the PFC right total, white matter, gray matter (subtraction), PFC left total, and white matter and gray matter (subtraction) according to the disease severity $(\mathrm{p}>0.05)$ (Additional file 1 : Table S1). No statistically significant differences in the WCST-2, 4, 6, and 10 measurements and Stroop test difference between-1-5, Stroop test-5, Stroop test error, and Stroop test-5 correction measurements of the

Table 2 Polysomnographic findings of patient and control groups

\begin{tabular}{|c|c|c|c|c|}
\hline & Total $(n=43)$ & Patient $(n=28)$ & Control $(n=15)$ & $p^{a}$ \\
\hline \multicolumn{5}{|l|}{$\mathrm{AHI}(/ \mathrm{h})$} \\
\hline Min-max (median) & $0.50-93.10(16.5)$ & $6.50-93.10(30.8)$ & $0.50-4.30(2.3)$ & $0.001^{* *}$ \\
\hline \multicolumn{5}{|l|}{ NREM1 (\%) } \\
\hline Min-max (median) & $1.80-25.10(5.6)$ & $1.80-13.70$ (5.05) & $2.30-25.10(6.3)$ & 0.198 \\
\hline \multicolumn{5}{|l|}{ NREM2 (\%) } \\
\hline Min-max (median) & $2.70-70(22)$ & $4.20-70(20.05)$ & $2.70-52.70(35.4)$ & 0.386 \\
\hline \multicolumn{5}{|l|}{ NREM3 (\%) } \\
\hline Min-max (median) & $13.70-81.20$ (49.1) & 15.10-74.70 (49.7) & $13.70-81.20(37)$ & 0.241 \\
\hline \multicolumn{5}{|l|}{ REM (\%) } \\
\hline Min-max (median) & $0.90-24.30(13.4)$ & $4.30-24.30(12.8)$ & $0.90-23.80(15.7)$ & 0.516 \\
\hline \multicolumn{5}{|l|}{ Time $\mathrm{SO}_{2}<90 \%(\%)$} \\
\hline Min-max (median) & $0-29.60(0.2)$ & $0-29.60(0.9)$ & $0-0.40(0)$ & $0.001^{* *}$ \\
\hline \multicolumn{5}{|l|}{$\operatorname{Min} \mathrm{SO}_{2}(\%)$} \\
\hline Min-max (median) & $61-95(85)$ & $61-89(83)$ & 85-95 (93) & $0.001^{* *}$ \\
\hline
\end{tabular}

Table 3 Magnetic resonance imaging volumetric measurements of patient and control groups $^{3}$

\begin{tabular}{lll} 
Group & P \\
\hline Total $(n=43)$ & Patient $(n=28) \quad$ Control $(n=15)$
\end{tabular}

\section{PFC RT $\left(\mathrm{mm}^{3}\right)$}

Min-max (median) $\quad 39,693-74,861(58,662) \quad 39,693-70,979(58,321) \quad 45,404-74,861(59,453.28) \quad 0.300$ PFC RWM $\left(\mathrm{mm}^{3}\right)$

Min-max (median) 12,317-28,286 (19,073) 12,317-28,286 (19,036) 13,258-25,432 (19,073) $\quad 0.585$ PFC RGM (subtraction) $\left(\mathrm{mm}^{3}\right)$

Min-max (median) 27,376-49,429 (39,450) 27,376-46,554 (38,927) $\quad 32,146-49,429(39,987) \quad 0.152$

PFC LT $\left(\mathrm{mm}^{3}\right)$

Min-max (median) $\quad 36,005-77,029(61,300) \quad 36,005-77,029(58,552) \quad 42,237-74,080(61,300) \quad 0.365$

PFC LWM $\left(\mathrm{mm}^{3}\right)$

Min-max (median) $\quad 11,746-31,214(20,281) \quad 11,746-31,214(19,999) \quad 13,868-25,385(21,171) \quad 0.553$

PFC LGM (subtraction) $\left(\mathrm{mm}^{3}\right)$

Min-max (median) $\quad 24,023-48,694(40,357) \quad 24,023-48,209(40,289) \quad 28,368-48,694(40,921) \quad 0.348$

Student's $t$ test

PFC prefrontal cortex, RT right total, $R W M$ right white matter, $R G M$ right gray matter, $L T$ left total, $L W M$ left white matter, $L G M$ left gray matter 
cases according to the severity of the disease and MRI volumetric measurements were observed ( $\mathrm{p}>0.05$ ) (Table 5; Additional file 2: Table S2).

In addition, there was no statistically significant difference in the ESS results according to the disease severity $(\mathrm{p}>0.05$ ) (Additional file 3 : Table S3). No statistically significant correlations were found between the WCST-2, 4, 6, and 10 and Time $\mathrm{SO}_{2}<90 \%$ and $\min \mathrm{SO}_{2}$ measurements in the patient group ( $\mathrm{p}>0.05$ ) (Table 6).

On the other hand, we found a negative and statistically significant correlation between the WCST-4 and WCST-10 and ESS measurements ( $\mathrm{r}-0,452 ; \mathrm{p}$ 0.016; $\mathrm{p}<0.05 ; \mathrm{r}-0.437$; p $0.020 ; p<0.05$ ) (Table 6). However, no statistically significant correlation was found between the Stroop test-1-5, Stroop test-5, Stroop test\% error, Stroop test-5 correction measurements, and ESS, $\mathrm{Min} \mathrm{SO}_{2}$ and Time $\mathrm{SO}_{2}<90 \%$ measurements $(\mathrm{p}>0.05)$ (Table 6).

\section{Discussion}

Obstructive sleep apnea syndrome has been associated with a broad range of psychological problems and neurocognitive difficulties, particularly in memory and new learning, attention, and executive function, which are the most widely reported. Among the cognitive domains, executive function is the most affected domain (Saunamaki

Table 4 Wisconsin Card Sorting Test and Stroop Test scores of patient and control groups

\begin{tabular}{|c|c|c|c|c|}
\hline & \multicolumn{3}{|l|}{ Group } & \multirow[t]{2}{*}{$P$} \\
\hline & Total $(n=43)$ & Patient $(n=28)$ & Control $(n=15)$ & \\
\hline \multicolumn{5}{|l|}{ WCST-2 } \\
\hline Mean \pm SD & $52.72 \pm 24.15$ & $57.68 \pm 24.25$ & $43.47 \pm 21.79$ & \multirow[t]{2}{*}{0.061} \\
\hline Min-max (median) & 7-92 (55) & $7-92(61)$ & $11-78(54)$ & \\
\hline \multicolumn{5}{|l|}{ WCST-4 } \\
\hline Mean \pm SD & $3.72 \pm 1.77$ & $3.36 \pm 1.78$ & $4.40 \pm 1.59$ & \multirow[t]{2}{*}{0.052} \\
\hline Min-max (median) & $0-6(3)$ & $0-6(3)$ & $1-6(4)$ & \\
\hline \multicolumn{5}{|l|}{ WCST-6 } \\
\hline Mean \pm SD & $22.86 \pm 17.99$ & $27.18 \pm 19.02$ & $14.80 \pm 12.89$ & \multirow[t]{2}{*}{$0.022^{*}$} \\
\hline Min-max (median) & $0-82(20)$ & $0-82(22)$ & $0-45(11)$ & \\
\hline \multicolumn{5}{|l|}{ WCST-10 } \\
\hline Mean \pm SD & $47.28 \pm 19.79$ & $43.36 \pm 18.44$ & $54.60 \pm 20.77$ & \multirow[t]{2}{*}{0.061} \\
\hline Min-max (median) & $6-87(50)$ & $13-74(42.5)$ & $6-87(58)$ & \\
\hline \multicolumn{5}{|c|}{ Stroop test difference between $1-5$} \\
\hline Mean \pm SD & $19.47 \pm 8.78$ & $21.18 \pm 8.76$ & $16.27 \pm 8.17$ & \multirow[t]{2}{*}{0.061} \\
\hline Min-max (median) & $4-40(18)$ & $4-39(20)$ & $7-40(16)$ & \\
\hline \multicolumn{5}{|l|}{ Stroop test-5 } \\
\hline Mean \pm SD & $30.07 \pm 9.80$ & $32.25 \pm 10.10$ & $26.00 \pm 7.99$ & \multirow[t]{2}{*}{$0.043^{*}$} \\
\hline Min-max (median) & $15-55(28)$ & $15-55(30)$ & $16-49(24)$ & \\
\hline \multicolumn{5}{|l|}{ Stroop test-5 error } \\
\hline Mean \pm SD & $0.77 \pm 1.32$ & $0.82 \pm 1.19$ & $0.67 \pm 1.59$ & \multirow[t]{2}{*}{0.174} \\
\hline Min-max (median) & $0-5(0)$ & $0-4(0)$ & $0-5(0)$ & \\
\hline \multicolumn{5}{|c|}{ Stroop test-5 correction } \\
\hline Mean \pm SD & $1.51 \pm 1.53$ & $1.86 \pm 1.46$ & $0.87 \pm 1.51$ & \multirow[t]{2}{*}{$0.005^{* *}$} \\
\hline Min-max (median) & $0-6(1)$ & $0-5(1.5)$ & $0-6(1)$ & \\
\hline
\end{tabular}

Mann-Whitney U-test

WCST Wisconsin Card Sorting Test

${ }^{*} \mathrm{p}<0.05$; ${ }^{* *} \mathrm{p}<0.01$ 
and Jehkonen 2007). However, whether neurocognitive impairment is associated with excessive daytime sleepiness caused by chronic sleep fragmentation or recurrent apnea episodes still remains to be elucidated. The aim of the current study is to contribute

Table 5 Wisconsin Card Sorting Test and Stroop Test scores based on disease severity

\begin{tabular}{|c|c|c|c|c|}
\hline & \multicolumn{3}{|l|}{ Group } & \multirow[t]{2}{*}{ p } \\
\hline & Mild $(n=6)$ & Moderate $(n=8)$ & Severe $(n=14)$ & \\
\hline \multicolumn{5}{|l|}{ WCST-2 } \\
\hline Mean \pm SD & $51.0 \pm 25.91$ & $58.38-31.04$ & $60.14 \pm 20.42$ & \multirow[t]{2}{*}{0.690} \\
\hline Min-max (median) & $18-79(54.5)$ & $7-88(67.5)$ & 19-92 (61) & \\
\hline \multicolumn{5}{|l|}{ WCST-4 } \\
\hline Mean \pm SD & $3.83 \pm 1.83$ & $3.25 \pm 2.25$ & $3.21 \pm 1.57$ & \multirow[t]{2}{*}{0.773} \\
\hline Min-max (median) & $2-6(3.5)$ & $0-6(3)$ & $1-6(3)$ & \\
\hline \multicolumn{5}{|l|}{ WCST-6 } \\
\hline Mean \pm SD & $28.17 \pm 20.58$ & $26.25 \pm 18.15$ & $27.29 \pm 20.26$ & \multirow[t]{2}{*}{0.945} \\
\hline Min-max (median) & $5-60(27.5)$ & $0-62(22)$ & $4-82(21.5)$ & \\
\hline \multicolumn{5}{|l|}{ WCST-10 } \\
\hline Mean \pm SD & $51.0 \pm 18.69$ & $33.88 \pm 17.99$ & $45.5 \pm 17.61$ & \multirow[t]{2}{*}{0.215} \\
\hline Min-max (median) & $26-73(58.5)$ & $15-60(28)$ & $13-74(47)$ & \\
\hline \multicolumn{5}{|c|}{ Stroop test difference between $1-5$} \\
\hline Mean \pm SD & $19.67 \pm 9.79$ & $23.25 \pm 9.99$ & $20.64 \pm 8.05$ & \multirow[t]{2}{*}{0.716} \\
\hline Min-max (median) & $4-31(21.5)$ & $8-39(22.5)$ & $13-35(17)$ & \\
\hline \multicolumn{5}{|l|}{ Stroop test-5 } \\
\hline Mean \pm SD & $29.33 \pm 10.67$ & $36.63 \pm 8.26$ & $31.00 \pm 10.68$ & \multirow[t]{2}{*}{0.272} \\
\hline Min-max (median) & $15-42(30.5)$ & $25-48(36.5)$ & $20-55(27.5)$ & \\
\hline \multicolumn{5}{|l|}{ Stroop test-5 error } \\
\hline Mean \pm SD & $0.50 \pm 0.55$ & $0.38 \pm 0.74$ & $1.21 \pm 1.48$ & \multirow[t]{2}{*}{0.492} \\
\hline Min-max (median) & $0-1(0.5)$ & $0-2(0)$ & $0-4(1)$ & \\
\hline \multicolumn{5}{|c|}{ Stroop test- 5 correction } \\
\hline Mean \pm SD & $1.33 \pm 1.03$ & $2.13 \pm 1.46$ & $1.93 \pm 1.64$ & \multirow[t]{2}{*}{0.298} \\
\hline Min-max (median) & $0-3(1)$ & $1-5(1.5)$ & $0-5(2)$ & \\
\hline
\end{tabular}

Kruskal-Wallis Test

WCST Wisconsin Card Sorting Test

Table 6 Epworth Sleepiness Scale scores, Min $\mathrm{SO}_{2}$ and time $\mathrm{SO}_{2}<90 \%$ values by Wisconsin Card Sorting Test and Stroop Test in the patient group

\begin{tabular}{|c|c|c|c|c|c|c|}
\hline \multirow[t]{2}{*}{ Patient group $(n=28)$} & \multicolumn{2}{|l|}{ ESS } & \multicolumn{2}{|c|}{ Min $\mathrm{SO}_{2}(\%)$} & \multicolumn{2}{|c|}{ Time $\mathrm{SO}_{2}<90(\%)$} \\
\hline & $r$ & $\mathrm{p}$ & $\mathbf{R}$ & $\mathrm{p}$ & $r$ & $\mathrm{p}$ \\
\hline WCST-2 & 0.370 & 0.053 & 0.232 & 0.234 & 0.072 & 0.715 \\
\hline WCST-4 & 0.452 & $0.016^{*}$ & 0.213 & 0.277 & 0.070 & 0.722 \\
\hline WCST-6 & 0.126 & 0.522 & 0.044 & 0.823 & 0.024 & 0.904 \\
\hline WCST-10 & 0.437 & $0.020^{*}$ & 0.102 & 0.606 & 0.077 & 0.697 \\
\hline Stroop test $1-5$ difference & 0.087 & 0.660 & 0.052 & 0.793 & -0.026 & 0.895 \\
\hline Stroop test- 5 & 0.014 & 0.944 & -0.034 & 0.862 & 0.005 & 0.978 \\
\hline Stroop test-5 error & 0.223 & 0.254 & 0.002 & 0.991 & 0.137 & 0.488 \\
\hline Stroop test- 5 correction & -0.193 & 0.325 & -0.165 & 0.402 & 0.079 & 0.691 \\
\hline
\end{tabular}

$r$ Spearman's Correlation coefficient, WCST Wisconsin Card Sorting Test

${ }^{*} \mathrm{p}<0.05$ 
the understanding of the main causes of impairment of executive functions in OSAS. Impaired performance in OSAS has been reported in several tests of various cognitive functions, such as attention, vigilance, memory, psychomotor performance, and executive functioning (Aloia et al. 2004). Among those functions, recently, the most riveting is the executive function. Neuropsychologists define the executive function as a flexible approach under problematic conditions and maintenance and development of an organized condition (Dencla 1996; Eslinger 1996). Executive functions allow individuals to use their basic skills in a complex and variable environment in a coherent way (Eslinger 1996; Goldberg 2001). In the present study, we used the Stroop test to evaluate the focused attention, reaction inhibition, and speed of data processing and the WCST test to evaluate working memory, abstract thinking, perseveration, conceptualization, and executive functions. The WCST- 6 measurements were significantly higher in the patient group. It demonstrated that identity mapping skills in the patient group were particularly lower and that they had difficulty in actualization of changing response behavior which was expected, despite the instructions which were given.

Additionally, the Stroop test -5 and Stroop test -5 correction measurements were higher in the patient group, compared to the control group. This finding indicated that patients had more difficulty in the skills of changing the perceptional setup under distracting effect, inhibiting accustomed behavior patterns, and focused attention, compared to the control group. As a result, we observed problems in complicated attention and executive functions in the patient group. In addition, OSAS is accompanied by impairment in several cognitive domains, including attention and vigilance decrements, memory gaps, and abnormalities in executive functions (Saunamaki and Jehkonen 2007; Kim et al. 1997; Ferini-Strambi et al. 2003). The findings of the present study are consistent with the previous findings.

Furthermore, factors contributing to cognitive dysfunctions are not completely understood, yet (Beebe and Gozal 2002). The present study found a negative correlation between the WCST-4 and ESS measurements. The patients with higher ESS scores were observed to define a less number of categories, compared to patients with lower ESS scores $(p=0.016)$. This finding likely indicated that these patients had more difficulty in identity mapping and conceptual reasoning. In addition, it demonstrated that these patients had more difficulty in the expected changing response behavior, despite the instructions which were given, compared to the patients with lower ESS scores. Additionally, a negative correlation was observed between the WCST-10 and ESS measurements. The number of patients with higher ESS scores with the number of conceptual responses were statistically significantly lower than the patients with lower ESS scores $(\mathrm{p}=0.020)$. This likely indicated that these patients had more difficulty in learning rules, maintaining matching, and conceptual reasoning, compared to the patients with lower ESS scores and also demonstrated that the working memory of these patients was weaker.

However, we found no correlation between the WCST and Stroop subgroups and Time $\mathrm{SO}_{2}<90 \%$ and $\mathrm{Min} \mathrm{SO}_{2}$ measurements. In a study by Shpirer et al. (2012), the authors found no correlation between the executive functions and sleep parameters. However, attention, AHI, and hypoxemia parameters (mean $\mathrm{spO} 2$ and percent time spent with a $\mathrm{SpO} 2<90 \%)$ were correlated, although no association of these with the 
severity of sleepiness was detected. Furthermore, in another study by Bucks et al. (2013), sleep fragmentation was found to have a more strong effect on attention and vigilance, compared to hypoxemia (Bucks et al. 2013). Consistent with our study findings, Torelli et al. (2011) also found no correlation between neuropsychological functions and respiratory data. In another study, both excessive daytime sleepiness and nocturnal hypoxemia were found to equally contribute to cognitive deficits (Engleman and Joe 1999; Engleman et al. 2000).

In contrast to our findings, Bedard et al. (1991) and Cheshire et al. (1992) reported that dysfunction in executive functions was correlated with blood gas abnormalities and sleep interruption, rather than excessive daytime sleepiness. We also found that excessive daytime sleepiness more affected the impairment of attention and executive function, rather that hypoxemia and AHI.

Furthermore, patients need excess sleep the day after due to sleep interruptions secondary to repeated apnea, hypopnea, and arousals during sleep (Schlosshan and Elliott 2004; Douglas and Polo 1994). Daytime excessive sleepiness is the most commonly seen symptom among patients with OSAS (Karakoç et al. 2007; Mediano et al. 2007; Banno and Kryger 2007). However, not all patients with OSAS complain of daytime sleepiness. Pathophysiological causes of excessive daytime sleepiness are not completely understood to date. The level of the complaints of daytime sleepiness may individually vary in patients who share the same demographic characteristics and the same AHI values. The current study did not find any relationship between the disease severity of OSAS and ESS. The mechanisms of this condition are still unclear (Roure et al. 2008). On the other hand, the severity of sleepiness may not be associated with the severity of the disease (Banno and Kryger 2007). Mediano et al. (2007) reported that patients with daytime sleepiness had shorter sleep latencies, increased sleep effectivity, and poor nocturnal oxygenation, compared to individuals who did not have daytime sleepiness. Although the association of OSAS and daytime excessive sleepiness has been known for a long time, daytime cognitive and behavioral dysfunction, which seems to be beyond accompanying simple sleepiness, has been documented with the behavioral research conducted for the past two decades (Arens 2000; Marrone 1998).

In the patient group of this study, no correlation was detected between the disease severity of OSAS and attentive and executive functions. In a review by Bucks et al. (2013), five published articles were analyzed and disease severity was not associated with cognitive functions in three of them. Also, in another study by Borges et al. (2013), no significant correlation was found between AHI and executive performance. These findings are also consistent with our study findings.

The PFC serves for special executive functions (Bradley and Floras 2000). Disorders associated with OSAS affect PFC-related cognitive functions during the restorative phase of sleep (Beebe and Gozal 2002). In a study by Beebe and Gozal (2002), dysfunction in the PFC of the brain was demonstrated in patients with OSAS. In addition, PFC dysfunction was demonstrated to be associated with sleep disorders in several studies (Harrison and Horne 1997, 1998, 1999, 2000). These functional differences are related to the structural tissue damage and metabolic stress in various brain tissue compartments. On the other hand, previous neuroimaging studies performed in patients with OSAS demonstrated controversial results. In the present study, PFC volume measurements were similar in the 
patient and control groups, and had no correlation with the disease severity. However, MRI was inadequate to demonstrate the overt cerebral damage in a study conducted by Davies et al. (2001). Functional MRI studies may show occult neuronal dysfunction better than morphological MRI. Positron emission tomography (PET) study performed by Yaouhi et al. (2009) showed reduced PFC metabolism. Also, reduced activity in the prefrontal gyri was detected by functional MRI in a study by Zhang et al. (2011). In a review published in 2006, Zimmermen and Aloia (2006) reported either the absence of activation in the dorsolateral PFC or increased neuronal response in the frontal lobe, when a cognitive task was applied in functional neuroimaging cognitive studies. Hence, more sensitive and quantitative MRIs seem to be more successful in demonstrating the specific regions of the brain in cognitive functions in patients with OSAS, rather than volumetric MRI studies.

Functional magnetic resonance imaging (MRI) studies in neuroradiology demonstrated that the WCST and Stroop tasks are associated with different regions of the prefrontal region. Findings obtained under the Stroop task can be localized mainly in the left frontal lobe, and WCST success mainly in the right frontal lobe (Karakaş and Karakaş 2000; Yaouhı et al. 2009). In this present study, although no difference was found in the PFC volumes between the patient and control groups, a negative correlation close to statistical significance was achieved between the PFC left total volumetric measurement and Stroop test -5 correction test results in the patient group. A correlation close to statistical significance was also observed between the PFC left white matter volumetric measurement and Stroop test- 5 correction test results. Of note, we performed the measurements with structural volumetric MRI, while previous studies were carried out using the functional MRI. However, we believe that this finding is invaluable to demonstrate the correlation between the Stroop test and left frontal lobe and also is consistent with the previous findings in terms of localization.

\section{Conclusion}

In conclusion, impairment in executive functions is evident in OSAS. The most influential factor affecting this impairment is excessive daytime sleepiness, rather than hypoxemia and severity of the disease. Functional MRI which is more sensitive and more quantitative seems to be more successful in the visualization of specific regions of the brain, rather than volumetric MRI in cognitive functions in patients with OSAS.

\section{Additional files}

Additional file 1: Table S1. Evaluation of MRI volumetric measurements by disease severity.

Additional file 2: Table S2. Comparison of MRI volumetric measurements and neuropsychological tests in the patient group.

Additional file 3: Table S3. Evaluation of ESS by disease severity.

Authors' contributions

ZY: Preparation, planning and writing of the article, patient evaluation. NV: Image analysis and measurement, writing of the article. El: Patient evaluation, writing of the article. PBŞ: Patient evaluation. RT: Patient evaluation. All authors read and approved the final manuscript.

Author details

${ }^{1}$ Clinic of Neurology, Kocaeli Derince Education and Research Hospital, Kocaeli, Turkey. ${ }^{2}$ Clinic of Radiology, Kocaeli Derince Education and Research Hospital, Kocaeli, Turkey. ${ }^{3}$ Clinic of Psychiatry, Kocaeli Derince Education and Research Hospital, Kocaeli, Turkey. ${ }^{4}$ Clinical of Physical Medicine and Rehabilitation, Kocaeli Derince Education and Research Hospital, Kocaeli, Turkey. 


\section{Competing interests}

The authors declare that they have no competing interests.

\section{Ethical approval}

All procedures performed in studies involving human participants were conducted in accordance with the ethical standards of the institutional and/or national research committee and with the 1964 Helsinki Declaration and its updated amendments or comparable ethical standards.

\section{Informed consent}

An informed consent was obtained from each participant included in the study.

Received: 23 March 2016 Accepted: 27 October 2016

Published online: 08 November 2016

\section{References}

Aloia MS, Arnedt JT, Davis JD et al (2004) Neuropsycological sequelae of obstructive sleep apnea-hypopnea syndrome. A critical review. J Int Neuropsychol Soc 10:772-785

Arens R (2000) Obstructive sleep apnea in childhood. In: Loughlin GM, Carroll JL, Marcus CL (eds) Clinical features, in sleep and breathing in children: a developmental approach. Marcel Dekker, New York, pp 575-600

Baddeley AD, Logie RH, Bressi S et al (1986) Senil dementia and working memory. Q J Exp Psychol 14:585-589

Banno K, Kryger MH (2007) Sleep apnea: clinical investigations in humans. Sleep Med 8(4):400-426

Bedard MA et al (1991) Obstructive sleep apnea syndrome: pathogenesis of neuropsychological deficits. J Clin Exp Neuropsychol 13:950-964

Beebe WD, Gozal D (2002) Obstructive sleep apnea and the prefrontal cortex: towards a comprehensive model linking nocturnal upper airway obstruction to daytime cognitive and behavioral deficits. J Sleep Res 11:1-16

Borak J, Cieslicki J, Koziej M et al (1996) Effects of CPAP treatment on psychological status in patients with severe obstructive sleep apnoea. J Sleep Res 5(2):123-127

Borges JG, Ginani GE, Hachul H et al (2013) Executive functioning in obstructive sleep apnea syndrome patients without comorbities: focus on the fractionation of executive functions. J Clin Exp Neuropsyhol 35(10):1094-1107

Bradley TD, Floras JS (2000) (eds) Sleep apnea: implications for cardiovascular and cerebrovascular disease. Dekker, New York

Bucks RS, Olaıthe M, Eastwood P (2013) Neurocognitive function in obstructive sleep apnoea: a meta-review. Respirology 18:61-70

Cheshire Ket al (1992) Factors imparing daytime performance in patients with sleep apnea/hypopnea syndrome. Arc Int Med 152:538-541

Davies CW, Crosby JH, Mullins RL et al (2001) Case control study of cerebrovascular damage defined by magnetic resonance imaging in patients with OSA and normal matched control subject. Sleep 24(6):715-720

Dencla MB (1996) A theory and model of executive function: a neuropsychological perspective. In: Lyon GR, Krasnegor NA (eds) Attention, memory, and executive function. Brookes Publishing, Baltimore, pp 263-278

Douglas NJ, Polo O (1994) Pathogenesis of obstructive sleep apnea, hypopnea syndrome. Lancet 344:653-655

Engleman H, Joe D (1999) Neuropsychological function in obstructive sleep apnoea. Sleep Med Rev 3:59-78

Engleman HM, Kingshott RN, Martin SE et al (2000) Cognitive function in the sleep apnea/hypopnea syndrome (SAHS). Sleep 23:102-108

Eslinger PJ (1996) Conceptualizing, describing, and measuring compenents of executive function: a summary. In: Lyon GR, Krasnegor NA (eds) Attention, memory, and executive function. Paul H. Brookes Publishing, Baltimore, pp 67-395

Ferini-Strambi L, Baietto C, Di Gioia MR et al (2003) Cognitive dysfunction in patients with obstructive sleep apnea (OSA): partial reversibility after continous positive airway pressure (CPAP). Brain Res Bull 61(1):87-92

Goldberg E (2001) The executive brain: frontal lobes and the civilized mind. Oxford University Press, Oxford

Harrison Y, Horne JA (1997) Sleep deprivation affects speech. Sleep 20:871-877

Harrison Y, Horne JA (1998) Sleep loss impairs short and novel language tasks having a prefrontal focus. J Sleep Res 7:95-100

Harrison Y, Horne JA (1999) One night of sleep loss impairs innovative thinking and flexible decision making. Organ Behav Hum Decis Process 78:128-145

Harrison Y, Horne JA (2000) The impact of sleep deprivation on decision making: a review. J Exp Psychol 6:236-249

Horne JA (1998) Why we sleep. Oxford University Press, Oxford

Insausti R, Juottonen K, Soininen H, Insausti A, Partanen K, Vainio P, Laakso MP, Pitkanen A (1998) MR volumetric analysis of the human entorhinal, perirhinal, and temporopolar cortices. AJNR Am J Neuroradiol 19:659-671

Izci B, Ardic S, Firat H et al (2008) Reliability and validity studies of the Turkish version of the Epworth Sleepiness Scale. Sleep Breath 12(2):161-168

Karakas S (2006) Bilnot battery handbook: research and development studies of neuropsychological tests. Erylmaz Offset Matbaacilık Gazetecilik, Ankara

Karakaş S, Karakaş HM (2000) A multidisciplinary approach to researching executive functions: from cognitive psychology to neuroradiology. Klinik Psikiyatri 3:215-227

Karakoç Ö, Akçam T, Gerek M et al (2007) Reliability of the Epworth sleepiness scale on snoring and sleep apnea patients. KBB Forum 6(3):86-89

Kim HC, Young T, Matthews CG et al (1997) Sleep-disordered breathing and neuropsychological deficits. A populationbased study. Am J Respir Crit Care Med 156(6):1813-1819 
Lezak MD (1995) Neuropsychological assesment, 3rd edn. Oxford University Press, Newyork

Maquet P (1995) Sleep function (s) and cerebral metabolism. Behav Brain Res 69:75-83

Marrone O (1998) What is the evidence that obstructive sleep apnoea is an important illness? Monaldi Arch Chest Dis 53:630-639

Mediano O, Barceló A, de la Peña M et al (2007) Daytime sleepiness and polysomnographic variables in sleep apnea patients. Eur Respir J 30(1):110-137

Oktem O (2006) An Introduction to Behavioral Neurophysiology. Nobel Medical Publishers, Istanbul

Pennington BF, Ozonoff S (1996) Executive functions and developmental psychopathology. J Child Psychol Psychiatr 37:51-87

Rademacher J, Galaburda AM, Kennedy DN et al (1992) Human cerebral cortex: localization, parcellation, and morphometry with magnetic resonance imaging. J Cognit Neurosci 4:352-374

Roure N, Gomez S, Mediano O et al (2008) Daytime sleepiness and polysomnography in obstructive sleep apnea patients. Sleep Med 9(7):727-731

Saunamaki T, Jehkonen M (2007) A review of executive functions in obstructive sleep apnea syndrome. Acta Neurol Scand 115:1-11

Schlosshan D, Elliott MW (2004) Clinical presentation and diagnosis of the obstructive sleep apnoea hypopnoea syndrome. Thorax 9:347-352

Shpirer I, Elizur A, Shorer R et al (2012) Hypoxemia correletes with attentional dysfunction in patients with obstructive sleep apnea. Sleep Breath 16:821-827

Spreen O, Strauss E (2007) Compendium of neuropsychological tests: administration, norms and commentary. Oxford University Press, New York

Torelli F, Moscufo N, Garreffa G et al (2011) Cognitive profile and brain morphological changes in obstructive sleep apnea. Neuroimage 15; 54(2):787-793

Watson C, Clifford RJ, Cendes F (1997) Volumetric magnetic resonance imaging clinical applications and contributions to the understanding of temporal lobe epilepsy. Arch Neurol 54:1521-1531

Yaouhı K, Bertran F, Clochon P et al (2009) A combined neuropsychological and brain imaging study of obstructive sleep apnea. J Sleep Res 18:36-48

Zhang X, Ma L, Li S, Wang L (2011) A functional MRI evaluation of frontal dysfunction in patients with severe obstructive sleep apnea. Sleep Med 12(4):335-340

Zimmermen ME, Aloia MS (2006) A review of neuroimaging in obstructive sleeep apnea. J Clin Sleep Med 2(4):461-471

\section{Submit your manuscript to a SpringerOpen ${ }^{\circ}$ journal and benefit from:}

- Convenient online submission

\section{- Rigorous peer review}

- Immediate publication on acceptance

- Open access: articles freely available online

High visibility within the field

- Retaining the copyright to your article

Submit your next manuscript at $\boldsymbol{\nabla}$ springeropen.com 